\title{
Paul Strand y las paradojas de la modernidad americana
}

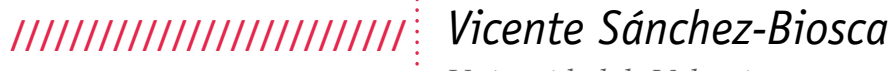

Universidad de Valencia

(España) 
Resumo

As contribuições de Strand para o cinema estão estreitamente relacionadas com seus trabalhos fotográficos da época e mesmo com um olhar que, apesar de suas múltiplas diferenças, possui muitos pontos em comum. Se em Manhatta (1920), Strand (em colaboração com Sheeler) oferece uma síntese da natureza e da modernidade, em Redes (1934) o que predomina, em contrapartida, é a experiência da arte muralista mexicana e a influência de Eisenstein (em suas andanças por México) são os fatores que determinam seus esforços na construção de uma épica dos operários. Mas sem dúvida, o projeto mais ambicioso de Strand (ao mando da produtora Frontier Films) foi Native Land, o filme que atendeu às demandas do American Popular Front e as moldou nas palavras dos fundadores da pátria americana.

\section{Palavras-chave}

Cinema, Srtrand, fotografia e Native Land.

\section{Abstract}

Paul Strand's contributions to the film world are very closely related to his photography work from each era, and even more to a world vision that, despite its different emphases, has many points in common. While in Manhatta (1920) Strand (along with Sheeler) offers a synthesis of nature and modernity, in Redes (1934) it is the experience of Mexican mural art and the influence of Eisenstein (on his way through Mexico) that determine his efforts to build a workingman's epic. But without a doubt, Strand's most ambitious project (at the head of the production company Frontier Films) was Native Land (1942), the film that took on the demands of the American Popular Front and engraved them in the words of the founding fathers of the American homeland.

\section{Key-words}

Paul Strand contributions, photography work, Native Land. 


\section{Naturaleza y urbe en 1920}

Manhatta, el mítico film realizado en 1920 por el pintor y fotógrafo Charles Sheeler y el fotógrafo Paul Strand, se cierra con un bello atardecer cayendo como un manto sobre la bahía del Hudson. Las nubes cubren el astro en su decadencia mientras nosotros, espectadores, sentimos el privilegio otorgado por esa visión elevada del imponente panorama natural; una perspectiva que sobrepasa las limitaciones físicas humanas, como si la cámara hubiese querido regalarnos con un don divino. La retirada de los últimos barcos vespertinos compone un hermoso cuadro que evoca la contemplación jubilosa de la naturaleza en su pureza todavía incontaminada. Es éste un plano insólitamente prolongado, diríase que consciente de su funcionalidad en la clausura de la película.

Viene precedido de un cartel que reza así:

$$
\begin{aligned}
& \text { Gorgeous clouds of sunset! } \\
& \text { drench with your splendor } \\
& \text { me or the men and women } \\
& \text { generations after me. }
\end{aligned}
$$

No son éstas palabras que haya que atribuir a los artistas que firman la película; son expresiones prestadas por una bien legitimada voz, un clásico de aureola legendaria en la literatura y el pensamiento norteamericanos: Walt Whitman. Pertenecen a un poema de su 
Leaves of Grass (Hojas de hierba), esa obra obsesivamente corregida y ampliada por su autor, desde su primera aparición en 1855 hasta el final de su vida, y expresión emblemática del ansia de libertad y hermandad que encarnaría la más genuina América. El poemario no vino solo. El lustro en el que Hojas de hierba amanecía al mundo, lo hacían también obras tan seminales como La letra escarlata (1850), de Nathaniel Hawthorne, Moby Dick (1851), de Herman Melville, y Walden (1854), de Henry David Thoreau. Toda una síntesis del alma norteamericana.

A pesar de los 65 años que separan Manhatta de Hojas de hierba, llaman la atención las semejanzas entre el espíritu de aquel hombre que en 1855 festejaba la libertad, la naturaleza y la hermandad y describía la visión fascinante de la bahía de Manhattan vista desde el ferry de Brooklyn (este poema data de 1860), y el imponente plano de la bahía que da el broche final a la película de Strand y Sheeler.

El cuadro que pintó Whitman algo tenía de místico:

Pero ¿qué me puede parecer más majestuoso y admirable que Mannhattan cuajada de mástiles?

¿El río, la puesta de sol y las olas de bordes recortados de la marea? ¿Las gaviotas agitando sus cuerpos, el barco de grano en la penumbra y la lenta gabarra?

¿Qué dioses pueden superar a estos que me llevan de la mano, y que con voces que quiero me llaman presto y en alto por mi nombre más intimo cuando me acerco? (WHITMAN, 1999, p.286)

Sin embargo, algo chocará a quien se zambulla en esta breve película de menos de diez minutos de duración, pues Manhatta no es el canto lírico sobre la naturaleza de esa isla de nombre indígena; es, por el contrario, una obra moderna, concebida en pleno auge del desarrollo tecnológico y urbanístico, un canto a la megalópolis desbordante de símbolos de la modernidad (las masas, la técnica, los rascacielos, la zona financiera de Wall Street, los ferrocarriles...). Por si fuera poco, el medio que la representa - el cinematógrafo- es a su vez una máquina moderna; como máquina moderna es la fotografía que los artífices del film habían utilizado con anterioridad para captar los signos de la gran urbe neoyorkina y que sirvieron al tiempo de 
1. La llamada Ashcan School de artistas neoyorkinos de principios de siglo (Robert Henri, John Sloan, George Luks, Everett Shinn, William

Glackens) pretendía retratar sin glamour ni idealizaciones la vida cotidiana de la capital. Lo cierto es que esta nueva visión urbana surgía al calor de un entramado plástico que incluía pintura, fotografía, pero también prensa, tanto la popular como los magazines de lujo Harper's o Scribner (Mottet 1998, p.114).

2. Sobre la originalidad de este período de Strand, Hambourg (1998); sobre la relación entre modernidad, americanismo y straight photography, Haworth-Book (1997) y de Chassey (2001, p.21-29). banco de pruebas y de modelo para la iconografía de Manhatta, que, como rezan sus títulos de crédito, se declara 'fotografiada' (en lugar de filmada o dirigida) por sus autores.

En efecto, Strand llevaba a sus espaldas varios años registrando, con su cámara fotográfica, los signos de su época y su lugar. Desde su visita a la Photo-Secession Gallery que Alfred Stieglietz y Edward Streichen habían abierto en el número 291 de la Quinta Avenida neoyorkina, Strand se había convertido en un bastión fundamental del movimiento moderno en fotografía. Superando el realismo social de la llamada Ashcan School, Strand se había internado en ese estilo que se denominó straigth photography, donde objetividad, americanismo y maquinismo se daban la mano. ${ }^{1}$ La revista Camera Work, que se alejaba cada vez más del pictorialismo y del simbolismo de sus comienzos, será el soporte en el que, desde 1916, Strand va publicando sus decisivos trabajos, como The White Fence (1916) o Blind Woman (1916). ${ }^{2}$ No extraña constatar que Manhatta lleva en sus encuadres huellas bien visibles de muchas de estas fotografías, como Wall Street (1910), literalmente reutilizada para el film, o Fifth Avenue (1916); mas también son reconocibles las trazas de algunos trabajos de Stieglietz (valgan como ejemplo The City of Ambitions y The Ferry Boat, ambas de 1910 y aparecidas en Camera Work durante el año siguiente).

Por su parte, Charles Sheeler se hallaba implicado en la pintura vanguardista y sus trabajos cubistas, así como su interés por las máquinas y la técnica revelan una fuerte imaginería moderna. Sheeler se contaba entre los pintores americanos que expusieron en el famoso Armory Show de 1913, acontecimiento decisivo para la aclimatación y desarrollo de la vanguardia en Nueva York y él fue quien fotografió nada menos que el celebérrimo $\mathrm{Nu}$ descendant l'escalier, de Marcel Duchamp. Como ha señalado Jan-Christopher Horak (1995, p.274), el trabajo de Sheeler posterior a Manhatta se vio poderosamente influido por las investigaciones formales desarrolladas con Strand para el film común.

Dicho brevemente, por sus temas, su iconografía, sus medios de expresión y sus referentes estilísticos inmediatos, Manhatta es una obra rabiosamente moderna e, incluso, forjada en un estilo vanguardista. En realidad, el estatismo de muchos de sus planos, que le fue criticado en repetidas ocasiones, demuestra una alta dosis de abstracción que el clásico ensayo de Lewis Jacobs ya reconocía: 
"Las tomas desde ángulos cuidadosamente elegidos daban lugar a composiciones casi abstractas" (JACOS 1972, p.349). En realidad, fue el mismo Strand, con motivo del estreno, quien subrayó la deliberada abstracción de su film, ayudando con ello a inscribirla en el contexto artístico e, incluso, cinematográfico:

Al limitarse a la geometría elevada del lower Manhattan y sus alrededores, con su nota distintiva, los fotógrafos [sic] han tratado de captar directamente las formas vivas que se les presentaban y reducir, mediante la más rigurosa selección, volúmenes, líneas y masas a sus términos de expresividad más intensos. A través de ello el espíritu se manifiesta. Han intentado hacer un 'scenic' con objetos naturales, mientras El gabinete del Dr. Caligari lo hacía mediante decorados pintados (HORAK 1995, p.272)

No sería nada exagerado hallar incluso entre estos planos abstractos algunas composiciones que mucho tienen que ver con el constructivismo posterior. En todo caso, la propia circulación del film confirma su dimensión vanguardista, pues, aunque estrenado en la sala comercial neoyorkina Rialto Theater el 24 de julio de 1921, este ‘scenic' se convirtió en seguida en una 'cult movie' que circularía por los llamados 'little cinemas', una suerte de cines de arte y ensayo avant la lettre; exhibición que siguió pautas incluso más decididas en Europa, cuya primera proyección tuvo lugar en una sesión dadaísta, en compañía de un film de Man Ray, la lectura de poemas de Apollinaire y la música de Eric Satie.

A ese breve documental le tocaría en suerte, por añadidura, asumir un papel de pionero en dos órdenes: por una parte, de la vanguardia experimental norteamericana, que por su extensísima tradición constituye una carga enorme, y, por otra, de las no menos exitosas y universales sinfonías urbanas que habían de invadir el mercado cinematográfico en los años sucesivos, como prueba, a título de ejemplo y sin ánimo exhaustivo, Rien que les heures (A. Cavalcanti, 1925), Twenty-Four Dollar Island (R. Flaherty, 19251927), Berlin, die Symphonie einer Grosstadt (W. Ruttmann, 1927), Autumn Fire y A City Symphony (Herman Weinberg, 1929 y 1930, respectivamente), El hombre con la cámara (Dziga Vertov, 1929), A Bronx Morning (Jay Leyda, 1931), City of contrasts (Irving Browning, 1931), 3 À propos de Nice (Jean Vigo, 1934), etc. Así pues, en cuanto
3. Recuérdese que Browning era también fotógrafo. 
culminación de un trabajo de figuración y como punto de arranque de una tradición, Manhatta constituye un acontecimiento de la modernidad a través de su emblema por excelencia, Nueva York.

A tenor de lo expuesto, resulta sorprendente que Strand y Sheeler apelen a un relato romántico como el de Whitman para sancionar su visión (recuérdese a este respecto que los carteles del film se inspiran de la misma fuente) y que clausuren ese paisaje urbano, esa culminación de tantos panoramas urbanos, con la citada imagen de una naturaleza incontaminada por la técnica. Dicho en otros términos, estamos muy lejos de la imaginería que late, por ejemplo, en Manhattan Transfer, la novela de John Dos Passos que en 1925 daría vida a todos los motivos de la modernidad (collage y montaje de técnica novelesca, representación de la urbe, masas, perspectivismo y fragmentación).

Horak ya constató esta esquizofrenia entre modernismo y romanticismo whitmaniano, pero Juan Antonio Suárez (2002, p.99) ha precisado más el diagnóstico definiendo Manhatta como un film panorama con autoconciencia cubista, en tanto en cuanto reproduce la ciudad como un espacio fracturado. Y concluye sobre la heterogeneidad del producto añadiendo nuevos factores: «Es a un mismo tiempo un documental, un afirmación crítica sobre la modernidad, una investigación estética sobre modelos, formas, movimientos y ritmos, y una contrapartida visual de las descripciones de la modernidad metropolitana producida por sociólogos, arquitectos y urbanistas contemporáneos» (SUÁREZ 2002, p.88).

Sin embargo, si atendemos a las peculiaridades de la modernidad norteamericana, las mezclas de Manhatta se muestran más sintomáticas y menos arbitrarias: desembocadura cinematográfica de una investigación sobre el paisaje urbano que se remonta a los panoramas de finales del XIX y se había investigado en el campo de la fotografía; expresión de las particularidades de la modernidad y la vanguardia neoyorkinas; encuentro entre un medio nuevo y un

4. Consúltese la minuciosa contextualización de los debates teóricos de la vanguardia cinematográfica norteamericana en Suárez (2003). fermento reflexivo previo; ${ }^{4}$ profecía de sinfonías urbanas, asiento de una tradición artística de film de arte; pero también acogida de ecos lejanos de una tradición americanista que funde naturaleza y ciudad en una síntesis que no considera contradictoria. Es esa imagen de una modernidad paradójica como la americana lo que explicaría la presencia destacada de Whitman y, a fin de cuentas, el carácter de símbolo en que se ha convertido el film de Strand y 
Sheeler. El hecho de que Strand retornara — o, tal vez, jamás llegó a abandonarla - a esta concepción se verá en las páginas que siguen.

\section{México: tras los pasos del muralismo y de Eisenstein}

Al filo de 1930, Paul Strand se interesa ardientemente por el paisaje natural y pasa parte del año 1932 en Nuevo México. En los años previos había descubierto la lucha de clases y su estancia en Nuevo México le familiarizó con el indigenismo. De ahí surgió su empeño por la captación fotográfica de la gente común.

Pero Strand no fue un viajero espontáneo, sino alguien reclamado desde instancias oficiales gracias a su amistad con Carlos Chávez, compositor y distinguido jefe del Departamento de Bellas Artes de la Secretaría de Educación, para realizar un film sobre la difícil situación de los pescadores de la zona de Alvarado. El proyecto estaba íntimamente ligado a sus preocupaciones y al trabajo fotográfico que realizó en el ínterin con las gentes de provincias. Strand fabricó una cámara con el objetivo disimulado en un lateral de la caja a fin de tomar sus instantáneas evitando tanto las poses artificiosas como el rechazo a ser fotografiado. Más tarde, en 1940, publicaría una carpeta titulada Photographs of México, compuesta por 20 fotos en láminas sueltas, acompañadas por un texto de Leo Hurwitz, personaje que reaparecerá en nuestro relato más adelante (FERNÁNDEZ, 1998). Ahora bien ¿qué significaba México para un artista (fotógrafo, pintor o cineasta) imbuido de espíritu moderno y de simpatías izquierdistas o, incluso, filocomunistas.

México era desde su revolución un escenario fascinante para la modernidad. Muchas de las disyuntivas que la vanguardia europea había resuelto mediante la negación de uno de los opuestos, se afrontaban aquí como una dialéctica osadísima y sin exclusiones: el enfrentamiento entre urbanización e indigenismo, la vanguardia y el realismo épico, la revolución y su conversión en programa de Estado, lo popular y lo moderno. El muralismo mexicano y sus tres gigantes, por otra parte tan diferentes entre sí (Rivera, Orozco y Siqueiros) fueron probablemente el síntoma más extremo de todos estos conflictos abiertos, pues los muralistas se apoyaron en la estética de las vanguardias, construyeron una monumental épica nacional, actuaron al servicio del Estado y militaron en las filas mar- 
xistas (EDER, 1991). Paul Strand no pudo por menos que sentirse conmovido por este proyecto.

Sin embargo, Strand seguía pasos muy influyentes y más cercanos a su medio de expresión. En efecto, el 9 de diciembre de 1930 había llegado a México, después de una estancia en Estados Unidos, el eminente director soviético Sergei M. Eisenstein en compañía de su ayudante Grigori Alexandrov y su operador Eduard Tissé y ocioso es añadir que le habían llevado al país las mismas razones y estímulos que más tarde iban a despertar la sensibilidad artística y social de Strand. Su objetivo era rodar un film sobre la revolución mexicana producido por el escritor Upton Sinclair. Aunque el destino del proyecto eisensteiniano fue aciago y el cineasta de Riga tuvo que abandonar el país a finales de 1931 con las manos vacías y la película inacabada, Eisenstein había dejado huellas indelebles de su paso por México.

Eisenstein, fascinado por el deslumbrante mundo en transformación que visitaba, fue prolijo en diseños preparatorios para su film Que Viva México!, en el que se proponía vertebrar la tradición popular y religiosa del país, la tierra árida y la escasa vegetación, los rostros ancestrales de sus habitantes y el folclore. Los motivos de varios de estos bosquejos son religiosos hasta el punto de ofrecer representaciones marcadamente sacrificiales. La veta local era un acicate para ensayar figuraciones extáticas tan del gusto del cineasta. Algunos, como los titulados Viva Cristo Rey (1931), Autógrafo, Éxtasis o Verónica, introducen, bajo una inspiración mexicana de catolicidad lacerante, la imaginería del pathos que tanto le interesó a lo largo de su vida, desde El acorazado Potiomkin (1925) hasta su último e inconcluso libro, La no-indiferente naturaleza (1945-1947).

Pues bien, Strand, sirviéndose de su cámara fotográfica, parece haber sido atraído por imágenes que proceden de esta pulsión eisensteiniana. Su Cristo (Tlacochoaya, Oaxaca, 1934), su Virgen (San Felipe, Oaxaca, 1932) o Calvario (Pátzcuaro, 1933), representando este último un conjunto escultórico con el cuerpo de Cristo descendido de la cruz, plagado de heridas y ensangrentado, traen a la memoria una escenografía muy cara a Eisenstein donde lo religioso es experimentado con reverberaciones barrocas. Ahora bien, si los alicientes son compartidos, las soluciones de ambos artistas difieren y la película Redes lo prueba ampliamente. 


\section{Redes: literatura obrera e imagen épica}

Fue en abril de 1934 cuando comenzó el rodaje de Redes en el poblado de pescadores de Alvarado, en Tlacotalpan y en la ribera del Papaloapan y se extendería hasta octubre del mismo año (GARCÍA RIERA, 1992, p.128).5 Strand había concebido el film y supervisó la producción actuando además como operador salvo en los primeros planos del agua. Fred Zinnemann fue el encargado de la dirección. El objetivo, según declaró el fotógrafo, era “darle al drama local una significación mayor y al tiempo mantenerlo dramáticamente real" (Rosenblum, 1993). Y, de hecho, sólo un actor profesional intervino en el rodaje, el que interpretaba al 'acaparador' (David Valle González). Sin embargo, el argumento, debido a Agustín Velásquez Chávez, era de gran esquematismo social y por momentos rayano en el melodrama. Su tema era la denuncia de la situación de miseria en que vivían los pescadores del golfo sometidos a la explotación de patronos avaros y sin escrúpulos. Siguiendo como hilo conductor la vida de Miro, cuyo hijo muere al rehusar el patrón prestarle ayuda para transportarlo al hospital y recibir asistencia médica, Redes es un cuerpo compuesto por dos líneas que se superponen sin alcanzar una buena articulación: por una parte, la trama narrativa, heredada de la literatura proletaria, que relata en trazos muy gruesos la conversión revolucionaria de Miro, su ascenso a la condición de líder y su posterior sacrificio, precio pagado para la toma de conciencia política y social de sus compañeros. Por otra parte, el tratamiento fotográfico y cinematográfico de los cuerpos, los rostros y la labor cotidiana de las gentes.

Las fuentes que se reconocen fácilmente en Redes son también elocuentes. En primer lugar, la monumentalización del pueblo a través de esos pescadores humildes pero recios entronca con el proyecto mitificador que habían emprendido los muralistas, aunque sin remontarse a los orígenes indígenas ni ofrecer una épica nacional. En segundo lugar, el trabajo documental ofrece, en aquellas escenas que por su naturaleza se despegan de las convenciones del relato obrero, una belleza fotográfica y una información etnológica de incalculable valor. Sucede esto en las largas secuencias que muestran el ritual de la pesca. Podría afirmarse que mientras el cine de Robert Flaherty documenta la lucha del hombre contra la naturaleza, el de Strand representa siempre la agónica lucha del hombre
5. Sin embargo, William Alexander (1990, p.149) afirma que el rodaje duró once meses y sitúa la instalación de Strand en la zona de Alvarado en febrero de 1934, aunque no ofrece una fecha precisa para el comienzo del rodaje. 
6. Las semejanzas merecerían un desarrollo: también La perla (1945) se desarrolla en un poblado de pescadores indígenas de México y también ahí el hijo del protagonista muere a causa

de una enfermedad. La militancia

de Steinbeck haría previsible más concomitancias, pero éstas se detienen en este punto. Steinbeck construye un relato de sabor fuertemente simbólico y mágico en torno a los poderes maléficos de la perla encontrada, mientras

Redes inscribe sus acontecimientos, como ya se ha dicho, en los códigos de la novelística obrera.

7. El abanico de actividades de la FPL fue abundante: distribución de films obreros, exhibición de los mismos, crítica en revistas y prensa, así como publicaciones especializadas (New Masses, Daily Worker, Experimental Cinema, New Theatre and Film...). En noviembre de 1933, la FPL formó la Potamkin Film School con Sam Brody, Leo Hurwitz, David Platt, Lewis Jacobs y Irving Lerner. Se trataba en todos los casos citados de contribuir al surgimiento de un público nuevo para la producción obrera. contra la injusticia y la explotación causadas por otros hombres, es decir, la lucha de clases. En tercer lugar, la estructura del film, algunos de cuyos episodios recuerdan The Pearl, ${ }^{6}$ la espléndida novelita de John Steinbeck, posee un carácter sacrificial en la línea eisensteiniana comentada más arriba que, a diferencia de Eisenstein, Strand virará hacia lo melodramático, presentando el sacrificio como parte de un discurso social y, en última instancia, político.

En cualquier caso, la relación de Strand con el film no llegó a ser muy distinta de la de Eisenstein con Que viva México!, pues, atrapado en el fuego cruzado de antagonismos personales y políticos entre los miembros de la Secretaría de Educación, Strand abandonó México a finales de 1934 sin ver la película concluida. $\mathrm{Al}$ retorno a su país le aguardaba un reto muy especial: llevar todas estas preocupaciones sociales al territorio propio, a su tradición y al sentido histórico de la lucha que ahora, con el crecimiento de los fascismos a mediados de los años treinta, se estaba generalizando.

\section{De la Workers' Film and Photo League a Frontier Films}

La historia neoyorkina de los movimientos de izquierda en el dominio de las artes, la cultura y el cine discurre en paralelo a los avatares experimentados por Paul Strand en México. La Workers' Film and Photo League se había creado en la ciudad de Nueva York por iniciativa de la Workers' International Relief en diciembre de 1930 (la WIR funcionaba desde 1921 y coordinaba numerosas organizaciones en todo el mundo). Como organismo militante, intervino en el campo de la producción editando un Workers' Newsreel con 16 números entre 1931 y 1934, cuyos motivos eran reivindicaciones de los trabajadores, protestas, manifestaciones, las llamadas 'marchas del hambre', etc., con el objetivo de oponer la propaganda obrera al discurso de los noticiarios comerciales.7 Un largometraje resultó de la agrupación de ese material, America Today.

Sin embargo, fue Nykino (nombre surgido de las iniciales de la ciudad de los rascacielos y del término ruso 'kino' que desvelaba la fuente de inspiración y militancia soviéticas) el organismo de izquierdas más radical, resultante de una escisión del FPL. Figuras como Leo Hurwitz, Ralph Steiner, Irving Lerner o el fotógrafo Sydney Meyers fueron decisivas en este giro político. Además, en 
1935, Hurwitz, Steiner y el propio Paul Strand habían sido contratados por la New Deal Resettlement Administration rooseveltiana para trabajar en el film The Plow that Broke the Plains, dirigido por Pare Lorentz que supondría una apuesta propagandística por el progreso social y la industrialización, organizado desde el gobierno. La radicalidad de la tríada chocó con la moderación de Lorentz y probablemente hizo más patente la necesidad de intervenir a través de iniciativas no institucionales. El hecho es que Nykino continuó la labor de su predecesor replicando al discurso del noticiario The March of Time, de la Time Inc., y en septiembre de 1936 dio a la luz dos entregas de noticiarios titulados The World Today, bajo la dirección de Michael Gordon. ${ }^{8}$

Mas fue en la primavera de 1937 cuando se puso en marcha la productora sin ánimo de lucro Frontier Films. Y a su cabeza, en calidad de presidente, encontramos a Paul Strand, mientras Hurwitz y Steiner actuaban como vicepresidentes, asistidos por un nutrido equipo de intelectuales con A. MaCLeish, John Dos Passos, Lilian Hellman, Aaron Copland, entre ellos. Su influjo fue mucho mayor y su producción más notable que los intentos previos por diversas razones. Una de las más importantes, si no la de mayor relieve, fue el amplio espectro político que representaba. Si la FPL había nacido de la política sectaria de la Komintern aprobada en 1928 que respondía a la estrategia radical de clase contra clase, Frontier nacía bajo el signo del Popular Front, que seguía las estrategias integradoras frentepopulistas en su lucha contra el fascismo (Wolfe, 1993: 361). El nombre - Frontier - se debía al título inglés de un film de Dovzhenko y su manifiesto presentaba la empresa como una organización cinematográfica independiente y sin ánimo de lucro dedicada a la producción de films realistas sobre la vida americana; films que reflejaran verídicamente la vida y el drama de la América contemporánea. Su bestia negra - en el dominio cinematográficoera Hollywood por su desinterés hacia la pobreza y su propósito era dar a conocer todo el material que la industria cinematográfica de Los Angeles elidía o ignoraba.

Su manifiesto habla más claro que cualquier paráfrasis: "Hay numerosos aspectos de la vida americana que la industria del cine ignora. En los turbulentos acontecimientos que llenan nuestros periódicos... en la vívida realidad de nuestra vida cotidiana... en los ricas y robustas tradiciones del pueblo americano... existe abundante
8. El estilo de The March of Time aporta una novedad sustancial al discurso de los noticiarios tradicionales que será retenido por los miembros de Frontier, como se verá especialmente en Native Land, a saber: la dramatización de hechos por medio de actores. 
material dramático. Éstos son los temas que necesita dramatizar el medio de entretenimiento más popular de América. Es precisamente esta América - el mundo en el que vivimos realmente - la que retratará Frontier" (CAMPBELL 1982, p.146).

Cinco fueron sus más notables intervenciones en el campo cinematográfico: el montaje en 1937 (en el que colabora Strand) de dos films, uno de ellos con material rodado por Herbert Kline en España (Heart of Spain) y el otro con metraje rodado por Harry Dunham sobre la invasión japonesa de China (China Strikes Back); a continuación, con Henri Cartier-Bresson y Kline de nuevo se montó un nuevo film sobre España (Return to Life); el cuarto, People of Cumberland (1938), fue un film político en torno a la Highlander Folk School de Tennessee, dirigido por Meyers y Jay Leyda. En cualquier caso, la producción más ambiciosa de Frontier Films, en la que Paul Strand puso personalmente toda la carne en el asador, como productor y como fotógrafo, fue Native Land (1942). A su vez, la organización se vació en un proyecto que, por su alcance, su duración, su coste, los conflictos que desencadenó y su abordaje programático de la historia norteamericana acarrearía el fin de la productora.

\section{Native Land: la revolución y el origen}

Strand se ocupó de la fotografía, Leo Hurwitz del montaje, Paul Robeson se hizo cargo de la voz narradora, así como de la interpretación de las canciones, la partitura musical fue obra de Marc Blitzstein. Basada en las investigaciones de La Follette Civil Liberties Committee del Senado norteamericano sobre espionaje en la vida sindical, Native Land (cuyo título durante los años previos a su estreno fue simplemente Production $\neq 5$ ) fue poco a poco ampliando su alcance y los motivos de su recorrido por la geografía y la historia de los Estados Unidos hasta alcanzar un carácter global y programático. Paralelamente, su rodaje, comenzado en 1938 con la modesta cantidad de 7000 dólares, se alargó durante cuatro años y medio, de modo que la producción tuvo que interrumpirse en varias ocasiones para conseguir nuevos fondos, varios miembros abandonaron el proyecto (Willard Van Dyke, Ralph Steiner lo hicieron en 1938), el guión fue rescrito y la empresa acabaría por absorber todo el potencial del grupo. 
En su estado definitivo, Native Land avistaba el problema de la degeneración de las ideas y las palabras fundadoras de América y su conversión en clisés bajo la amenaza siempre latente de la extorsión, el fascismo y la conspiración (ALEXANDER 1990, p.158). Por esta razón, la película se propone como recordatorio de las gestas mayores realizadas por los americanos, recuperando la voz de los padres de la patria y aplicándola al presente conflictivo en el que vivían los Estados Unidos durante los críticos años treinta. Bien puede hablarse de perspectiva global donde las expresiones clave serán "bill of rights", "build the liberty", "the pursuit of happiness" y como sujeto de todas ellas "We, the plain people".

Ahora bien, son éstos términos ambiguos por figurar en discursos muy distintos e incluso encontrados. Las ideas de 'Vida, libertad y 'pursuit of happiness' son reivindicaciones inalienables para un americano pues se remontan a la Declaración Americana de Independencia. Además, el poderoso movimiento populista, jeffersoniano y jacksoniano, ya había insistido en estas consignas bajo la faz de un ataque a los grandes negocios, pero la llegada de F. D. Roosevelt a la presidencia supuso el fin del populismo al gestionar aquél la mecanización y el progreso como empresa de la administración federal. Pese a todo, el cine dio en estos años un representante del populismo de gran calibre; una figura defensora de la igualdad de oportunidades, el liderazgo del hombre decente común (con el nombre de John Doe o de Mr. Smith), furibunda enemiga de la corrupción política y también recelosa y hostil ante los intelectuales. Esa figura, que pese a compartir muchas de las consignas señaladas, se halla en las antípodas de Native Land es Frank Capra. Será, pues, necesario, si queremos evitar asimilaciones precipitadas, repasar más de cerca el entramado de la película de Strand y Hurwitz con el fin de detectar qué separa su apuesta ideológica de otras que se trenzan con motivos aparentemente similares.

Este documento sobre la América contemporánea que repasa acontecimientos concretos de la lucha sindical en las ciudades, el racismo en el Sur, el fascismo del Ku Klux Klan, la extorsión económica, la conspiración en el trabajo y el espionaje en el seno de los sindicatos, entre otros temas, arranca zambulléndose muy atrás en el tiempo y trazando en sus primeros compases una historia doctrinal que en nada revela las premisas de la Internacional Comunista, sino más bien hinca sus raíces en la más genuina expresión de los 
padres fundadores del americanismo, de la libertad y de la declaración de derechos humanos.

El texto con el que el film se abre explicita su perspectiva:

Desde la fundación de nuestro país el pueblo americano hubo de luchar por su libertad en cada generación.

NATIVE LAND es un documento de la lucha de América por la libertad durante los últimos años.

Fue en esta lucha cuando los fascistas de nuestra tierra se vieron forzados a retirarse. Y el pueblo consiguió la fuerza democrática esencial para la unidad nacional y la victoria sobre el Eje.

Acto seguido, bajo el patronazgo de la voz over se despliega un montaje conceptual muy fragmentado. Las olas del océano se precipitan con violencia sobre las rocas. El narrador Paul Robeson explicita el sentido y la magnitud del retroceso histórico. 1620: "We cross the ocean". Es el encuentro de los colonos con este mundo nuevo y deslumbrante, una naturaleza límpida y salvaje que se abría a los ojos de los conquistadores; naturaleza que bellas imágenes presentan incontaminadas bajo la forma de montañas que rozan el cielo, bosques, ríos... La lectura de estos orígenes tiene algo de mítico: la primera mirada sobre la tierra, la conquista, la visión fascinada de la naturaleza. Sobre dicha naturaleza se construirán las casas, se enterrarán los primeros muertos y se conquistará la libertad.

Una cadena inquebrantable anudará los eslabones mencionados más arriba que constituyen la esencia misma de esta empresa histórica llamada América: la edificación de la libertad, la declaración de los derechos del hombre y, entre ellos, el derecho a la búsqueda de la felicidad. Desde la Conquista hasta la Independencia, desde la abolición de la esclavitud hasta la conquista del Oeste, desde el desarrollo de la máquina y la industrialización hasta la Gran Depresión: todo lleva la huella de unas palabras ensalmo cuya pérdida de vigor consiste precisamente en dar su sentido ya por adquirido ('take for granted', dar por hecho, es uno de los leitmotive más reiterados en el film). De este modo, lo que un día fue conquistado necesita ser renovado (reconquistado) a cada paso, pues numerosas son las amenazas que se ciernen sobre estos valores supremos del hombre americano. 


\section{La imagen: metáfora y premonición}

La audacia de Native Land radica en esa forma de dramatización de los hechos que no duda en apoyarse en material de archivo documental y combinarlo con reconstrucciones muy minuciosas de actores y una fotografía que Paul Strand hubo de cuidar al milímetro. Si Manhatta tomaba la forma de collage de fotografías y se autopresentaba como un film fotografiado, Native Land es un film rotundamente cinematográfico en el que el montaje desempeña un papel decisivo, tanto más comprometido cuanto que cose planos muy elaborados desde el punto de vista compositivo. Dos recursos merece la pena retener por su sistematicidad: la asociación metafórica y la anticipación narrativa; en ambos, el trabajo de la puesta en serie se combina con el de la composición plástica o, dicho en otros términos, el trabajo fotográfico se articula de forma productiva con el trabajo cinematográfico. Decisivo es para ello la forma genérica híbrida escogida: el documental dramatizado.

En los primeros minutos del film, cuando el narrador discurre sobre el papel de los pioneros que arribaron a este inmenso territorio virgen, un contrapicado acusadísimo nos muestra el tronco interminable de un árbol que, merced a la angulación, parece proyectarse contra el cielo. Acto seguido, un contrapicado muy semejante filma una columna inmensa blanca cuyos límites se prolongan igualmente más allá del encuadre. La asociación, apoyada por la voz del narrador, es más rica de lo que parece a simple vista: por una parte, traza un singular hiato entre el mundo de la naturaleza y la obra constructora del hombre; en segundo, interpreta la elipsis, no bajo la forma del contraste, sino la de la integración, la de la sintonía y la asociación natural; en tercero, proyecta la imagen de esa columna blanca hacia la forma simbólica en la que su forma se inspira, la de los capitolios, construidos en tantas capitales de Estados americanos, que representan a fin de cuentas la democracia del país. Dicho sintéticamente, la conversión en símbolo hace de los pilares naturales (del inmenso e inabarcable árbol) el sustento, no sólo de la obra de construcción humana (las casas, los hogares), sino de su dimensión social, la ley. Difícil es decir más con tan poco.

Un segundo ejemplo será extraído del primer episodio dramatizado del film, el de un granjero de Michigan que responde al 
nombre de Fred Hill (interpretado por Fred Johnson). Éste vive en bucólica armonía con la tierra cuando, al día siguiente de asistir a una reunión, recibe la 'visita' por unos trajeados asesinos a sueldo procedentes de la ciudad que acabarán con su vida. La escena transcurre con un casi táctil sabor de la tierra: el honrado labriego, su esposa empleada en la preparación de la comida, el hijo que ora auxilia a su padre en las tareas del arado, ora queda extasiado contemplando el límpido cielo. Repentinamente, un plano de detalle quiebra el clima pastoril y hogareño: una mano provista de ancho anillo golpea impaciente la portezuela de un vehículo. Mano ensortijada, automóvil y plano corto son tres verdaderos cuerpos extraños en el entorno que la escena nos ha pintado con tan vivo colorido natural. Como alertado por la intromisión, el montaje reacciona diseminando los focos de atención, multiplica los saltos en planos cada vez más breves y agitados: la mujer en la cocina, el hombre de regreso a casa, el niño tomando su relevo en el campo, el grupo de asesinos precipitándose en dirección a la mansión. Lo significativo de tanta fragmentación es que rehuya precisamente la mostración de la acción criminal; de hecho, los hombres salen precipitadamente en dirección a su automóvil, suben a él y abandonan el lugar a gran velocidad. La mujer salta de su silla y tropieza con el barreño repleto de agua en donde lavaba las patatas. Entonces, el barreño cae al suelo derramando sobre el suelo de madera toda la carga de su líquido y dejando impresa en él la mancha. El impacto del montaje es súbito e impresionante. Esta metáfora de la sangre derramada anticipa la visión por la mujer de su esposo ensangrentado y moribundo, pero al propio tiempo recuerda una asociación que Eisenstein colocó en su primer largometraje, La huelga (1924), cuando el tintero de los patronos se derramaba sobre el plano de la ciudad en terrible premonición de la masacre inminente sobre el cuerpo de los obreros. Eisenstein optó por la oscuridad viscosa y siniestra de la tinta, cuya asociación con la espesa sangre era inmediata e hiriente; Strand y su equipo connotan de forma terrible una imagen límpida donde las haya, extraída del mismo límpido mundo que describe: el agua transparente en la que se remojan los productos de la tierra que cae al suelo dibujando un caprichoso... presagio de muerte violenta. 


\section{Una mitología de la sintesis}

Hemos mencionado el recurso sistemático a las asociaciones. Una de ellas se ubica al final del preámbulo de Native Land; se trata de una asociación también revestida del ropaje de una elipsis. Cuando el narrador ha repasado algunas de las manifestaciones de la técnica construidas por el hombre americano, la cámara filma en acusadísimo contrapicado un aeroplano que surca el claro firmamento. Una vez el veloz avión abandona la imagen, la cámara desciende literalmente a pie de tierra para mostrar una yunta de bueyes conducida por un granjero. El contraste es de una radicalidad insólita, la asimilación no lo es menos. Del cielo dominado por ese hombre invisible que pilota la máquina moderna, nos deslizamos junto a ese otro hombre de carne y hueso, visible y recio, que labra la tierra con sus manos y con la ayuda de sus animales sin concurso alguno de la técnica.

Pocas veces en el interior de un mismo plano se harán perceptibles tantos contrastes: el cielo y la tierra, la técnica y la naturaleza, el hombre y la máquina. Pero esta afirmación es inexacta, porque entre las parejas que acabamos de enumerar hay asimilación al tiempo que paradoja, síntesis a la vez que contraste. Pues Native Land no se presenta como el canto a una de ellas en detrimento de la otra, sino una oda a la extraña dialéctica que las une. Quizá así habremos dado con la clave de esta película y acaso de una constante de la obra y la visión de Paul Strand a través de los años.

Y es que en Native Land no parece haber contradicción entre el canto a la naturaleza y el canto a la máquina, al desarrollo y a la industria, como tampoco lo habrá en muchos de los films producidos por la administración rooseveltiana del New Deal. A diferencia del futurismo, Strand concibe la máquina bajo el sello del hombre que la empuña; por esto, nada hay en él del manifiesto vertoviano que celebra la superación del hombre por la máquina, pues ésta aparece, si se nos permite la licencia, humanizada. "To bring the machines to life": la expresión es elocuente (y procede de Native Land). Tampoco hay incompatibilidad entre los fragmentos que recuerdan las sinfonías urbanas y la representación de parajes naturales en otras escenas. A diferencia de Berlín, sinfonía de una gran ciudad, por limitarnos a un ejemplo, el ritmo de la urbe y del trabajo, el del transporte y de la vida no son ajenos al hombre, sino producto suyo. 
9. Entiéndase en su justo término y al hilo de lo matizamos a continuación, pues la fotografía de Strand ya había representado lo humano con gran fuerza desde 1916 .
Si el hombre que sostiene este mundo puede calificarse de heroico, su heroísmo reside en su condición de hombre corriente; ese mismo ser que festejaba como sublime Walt Whitman y que Native Land formula reiteradamente con la expresión "We, the people". Reaparece, así, más de veinte años después de Manhatta, con un itinerario a sus espaldas de politización y militancia, de viajes y universalización, una mitología americanista que en Paul Strand es un retorno; un retorno al espíritu de los fundadores de la patria, a aquellos pensadores y actores que, como Emerson, Thoreau, Jefferson o John Brown, apuntaban, cierto que en una vertiente más formalista, en la primera obra cinematográfica de Strand una extraña síntesis de naturaleza y técnica, de tradición y modernidad.

Mas si la convergencia refuerza la paradoja de esa modernidad que late a más de veinte años de distancia, el hombre ha nacido entremedias en el universo de Strand, ${ }^{9}$ y lo ha hecho como un titán cuya misión será mantener viva la promesa de los padres fundadores, luchar por reconquistar y actualizar el significado de 300 años de lucha. Tal vez por ello Native Land, al aproximarse a su final, retorna a las montañas, con la visión, ahora enriquecida por la lucha sindical y obrera, de una naturaleza que es, como la ciudad, el hogar de América. Por eso también la bandera norteamericana ondeará al viento mientras la estatua de la libertad sanciona un futuro prometedor contra el enemigo que - dice el narrador en estos compases finales - se halla en el interior.

Espinosas y delicadas palabras para ser pronunciadas cuando el film por fin se estrenó, el 11 de mayo de 1942. No hacía ni seis meses de aquel 7 de diciembre en que la armada norteamericana había sido sorprendida y humillada sin previo aviso en Pearl Harbor. La maquinaria bélica norteamericana funcionaba ya a pleno rendimiento; a su servicio se puso la sociedad civil entera, cine incluido. Las denuncias respecto a conspiraciones que no tuvieran que ver con esa guerra habían de sonar, más que impertinentes, intolerables a oídos del gobierno y aun quizá de la sociedad.

Por esta razón, Frontier añadió a Native Land un epílogo leído por el mismo Paul Robeson que trataba de compensar la denuncia contenida en el film con la apuesta por una unidad nacional frente a la amenaza exterior representada por Hitler y el imperio japonés. Eran discursos demasiado contradictorios para que el público aprobara el equilibrio (ALEXANDER 1990, p.159). En realidad, 
este epílogo fue más tarde suprimido de las copias de la película. Era inevitable: Native Land supuso el final de Frontier Films, si bien muchos de sus miembros ya se hallaban en desbandada desde 1941, algunos precisamente implicados en los esfuerzos de guerra. Como recuerda oportunamente Russell Campbell, "la década de la Depresión había concluido y pasarían muchos años hasta que colectivos de izquierda comprometidos, como Frontier Films, reaparecieran de nuevo en América" (CAMPBELL 1982, p.164). No estamos ante el fin de un proyecto, sino, mucho más, ante el fin de una era.

\section{Bibliografia}

ALEXANDER, W. 1990. "Paul Strand as Filmmaker, 1933-1942", en Paul Strand. Essays on his life and work.

Nueva York: Aperture.

CAMPBELL, R. 1982. Cinema Strikes Back.

Radical Filmmaking in the United States 1930-1942. Michigan: UMI Research Press.

DE CHASSEY, E. 2001. “Pourquoi n'y a-t-il pas eu de grand art américain? (avant le triomphe de l'expressionisme abstrait), en Made in U.S.A. L'art américan, 1908-1947. París : Réunion des musées nationaux, pp.21-29.

EDER, R. 1991. "El muralismo mexicano: modernismo y modernidad", en Modernismo y Modernidad en el Arte Mexicano 1920-1950.

México: Instituto Nacional de Bellas Artes, pp. 67-81.

FERNÁNDEZ, H. 1998. "Paul Strand (y Anton Bruehl)", en Mexicana. Fotografía moderna en México 1923-1940, Valencia: IVAM, pp. 194-215.

GARCÍA RIERA, E. 1992. Historia documental del cine mexicano, vol. 1. Guadalajara: Universidad de Guadalajara. 
HAMBOURG, M. M. 1998. Paul Strand. Circa 1916.

Nueva York: Metropolitan Museum of Art.

HAWORTH-BOOK, M. 1997. Paul Strand. Nueva York: Aperture (1987, nueva edición en Colonia, Köneman).

HORAK, J. Ch. 1995. "Paul Strand and Charles Sheeler's

Manhatta", in Idem, ed., Lovers of Cinema.

American Film Avant-Garde 1919-1945.

Madison: University of Wisconsin Press.

JACOBS, L., "Cine experimental en Norteamérica 1921-1941", Hollywood Quarterly, vol. III, núm. 2 y 3 , invierno 1947-48 y septiembre de 1948 respectivamente. Recogido como apéndice La azarosa historia del cine americano. Barcelona: Lumen, 1972, vol. 2.

MOTTET, J. 1998. L'invention de la scène américaine.

Cinéma et paisaje. París: L'Harmattan.

RICHARDS, J. 1976. "Frank Capra and the Cinema of Populism", en Cinema ${ }^{\circ}$ 5, 1970, reproducido en Bill Nichols, ed., Movies and Methods. An Anthology, Berkeley/Los Angeles/Londres: University of California Press.

ROSENBLUM, N. 1993. "Strand/México", en México Through Foreign Eyes/Visto por ojos extranjeros 1850-1990, Nueva York y Londres: WW Norton \& Co.

SUÁREZ, J. A. “City Space, Technology, Popular Cultura: the Modernism of Paul Strand and Charles Sheeler's Manhatta", Journal of American Studies, 36 (2002).

SUÁREZ, J.A. 2003. "Fragmentos de un discurso olvidado: la primera vanguardia norteamericana y el cine", en Archivos de la Filmoteca $n^{\circ} 45$, octubre 2003, p.10-21,

WHITMAN, W: 1999. "A bordo del ferry de Brooklyn”, en Hojas de hierba. Madrid: Espasa-Calpe, edición de José Antonio Gurpegui, traducción de J.L. Chamosa y Rosa Rabadán.

WOLFE, Ch. 1993. "The Poetics and Politics of Nonfiction: Documentary Film”, en Grand Design. Hollywood as a Modern Business Enterprise, 1930-1939, Berkeley/Los Angeles/Londres: University of California Press. 